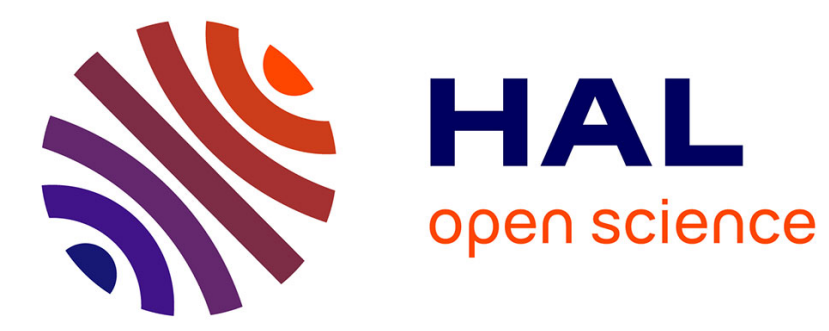

\title{
Segregation of hydrogen to defects in nickel using first-principles calculations: The case of self-interstitials and cavities
}

Damien Connétable, Yu Wang, Dôme Tanguy

\section{To cite this version:}

Damien Connétable, Yu Wang, Dôme Tanguy. Segregation of hydrogen to defects in nickel using firstprinciples calculations: The case of self-interstitials and cavities. Journal of Alloys and Compounds, 2014, vol. 614, pp. 211-220. 10.1016/j.jallcom.2014.05.094 . hal-01167534

\author{
HAL Id: hal-01167534 \\ https://hal.science/hal-01167534
}

Submitted on 24 Jun 2015

HAL is a multi-disciplinary open access archive for the deposit and dissemination of scientific research documents, whether they are published or not. The documents may come from teaching and research institutions in France or abroad, or from public or private research centers.
L'archive ouverte pluridisciplinaire HAL, est destinée au dépôt et à la diffusion de documents scientifiques de niveau recherche, publiés ou non, émanant des établissements d'enseignement et de recherche français ou étrangers, des laboratoires publics ou privés. 


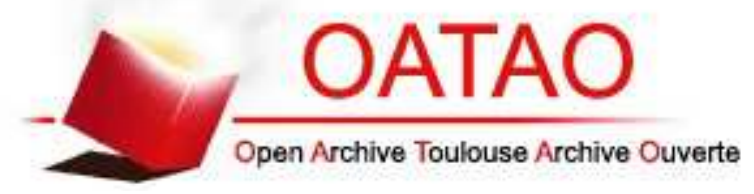

\section{Open Archive TOULOUSE Archive Ouverte (OATAO)}

OATAO is an open access repository that collects the work of Toulouse researchers and makes it freely available over the web where possible.

This is an author-deposited version published in : http://oatao.univ-toulouse.fr/ Eprints ID : 14028

To link to this article : doi: 10.1016/j.jallcom.2014.05.094

URL : http://dx.doi.org/10.1016/j.jallcom.2014.05.094

To cite this version : Connétable, Damien and Wang, Yu and Tanguy, Dôme Segregation of hydrogen to defects in nickel using firstprinciples calculations: The case of self-interstitials and cavities. (2014) Journal of Alloys and Compounds, vol. 614. pp. 211-220. ISSN 0925-8388

Any correspondance concerning this service should be sent to the repository administrator: staff-oatao@ listes-diff.inp-toulouse.fr 


\title{
Segregation of hydrogen to defects in nickel using first-principles calculations: The case of self-interstitials and cavities
}

\author{
Damien Connétable ${ }^{\mathrm{a}, *}$, Yu Wang ${ }^{\mathrm{b}, \mathrm{a}}$, Döme Tanguy ${ }^{\mathrm{b}}$ \\ a CIRIMAT, CNRS-INP-UPS UMR 5085, École Nationale d'Ingénieurs en Arts Chimiques et Technologiques (ENSIACET), 4, allée Émile Monso, BP 44362 , F-31030 Toulouse Cedex 4, France
} ${ }^{\mathrm{b}}$ Institut Lumière Matière, UMR 5306 Université Lyon 1-CNRS, Université de Lyon, 69622 Villeurbanne Cedex, France

Keywords:

Hydrogen

Segregation

Voids

Nickel

Embrittlement

DFT

\begin{abstract}
A B S T R A C T
A detailed first-principles study of the interactions of hydrogen with different point defects in $\mathrm{Ni}$ is presented. In particular we discuss the trapping of multiple hydrogen atoms in monovacancies, divacancies and at the self-interstitial (dumbbell). We show that, contrary to the previous theoretical works, the dumbbell cannot trap $\mathrm{H}$ atoms. In the case of a single vacancy, the segregation energy is found approximately equal to $-0.26 \mathrm{eV}$, in excellent agreement with implantation anneal experiments and thermal desorption spectra in the literature. This segregation energy is obtained for the relaxed octahedral (labeled $\mathrm{O}_{1}$ ) and tetrahedral $\left(\mathrm{T}_{1}\right)$ positions inside the vacancy, with a slight site preference for $\mathrm{O}_{1}$. Outside the vacancy, the binding energy becomes lower than $20 \mathrm{meV}$ after the second shell of octahedral sites $\left(\mathrm{O}_{2}\right)$. The $\mathrm{H}_{2}$ molecules are never stable inside the small vacancy clusters. Therefore, $\mathrm{VH}_{n}$ clusters show a maximum trapping capacity of six $\mathrm{H}$ atoms. In the case of the divacancy, the $\mathrm{H}$ segregation energy can be as low as $-0.4 \mathrm{eV}$. This reconciles theory and experiments by attributing the deepest trap energies to multiple vacancies.
\end{abstract}

\section{Contents}

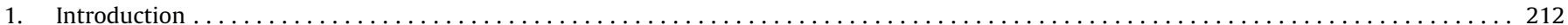

2. Methods $\ldots \ldots \ldots \ldots \ldots \ldots \ldots \ldots \ldots \ldots \ldots \ldots \ldots \ldots \ldots \ldots \ldots \ldots \ldots \ldots \ldots \ldots \ldots \ldots \ldots \ldots \ldots \ldots \ldots \ldots \ldots \ldots \ldots \ldots \ldots \ldots \ldots \ldots \ldots \ldots \ldots \ldots \ldots .212$

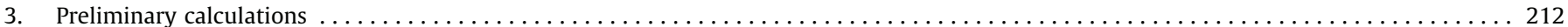

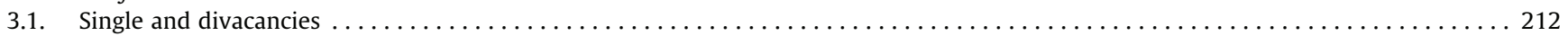

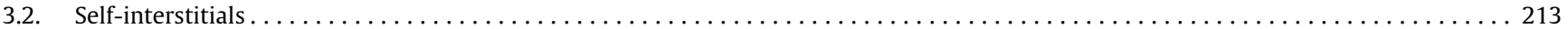

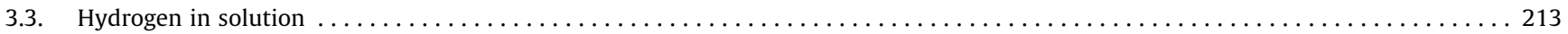

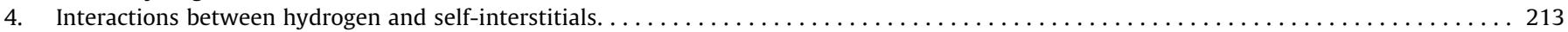

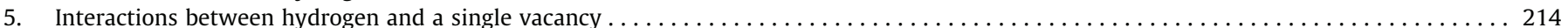

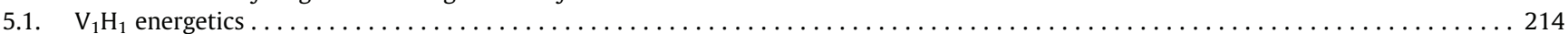

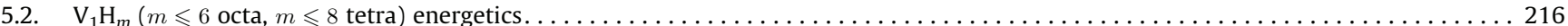

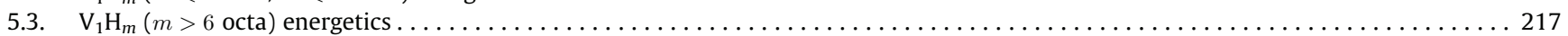

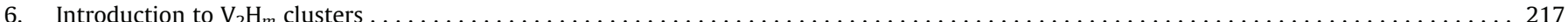

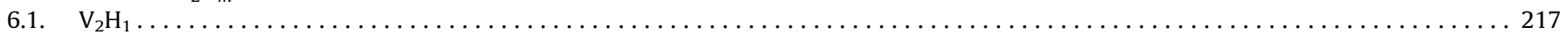

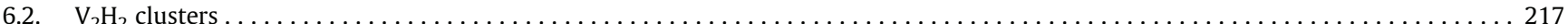

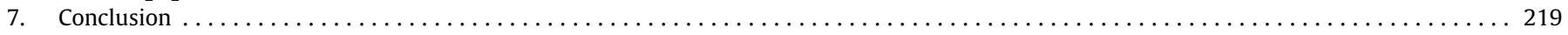

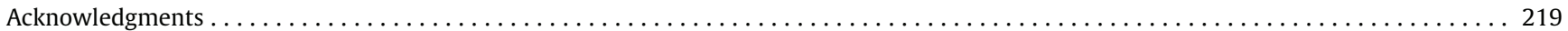

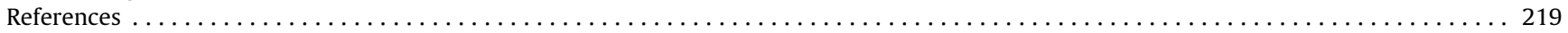

\footnotetext{
* Corresponding author. Tel.: +33 534323410 .

E-mail address: damien.connetable@ensiacet.fr (D. Connétable).
} 


\section{Introduction}

Hydrogen $(\mathrm{H})$ embrittlement of metals is a major concern because it is involved in most practical cases of aqueous stress corrosion cracking and fatigue. Despite considerable experimental efforts, the microscopic mechanisms are still debated with three competing mechanisms: decohesion [1], hydrogen enhanced localized plasticity [2] and local hydrides stabilized by stress [3,4]. Although decohesion is observed experimentally, at least for intergranular propagation (in $\mathrm{Ni}$ [5], in $\mathrm{Al}$ [6], for example), its quantitative modeling is not completed, as discussed in the review by Birnbaum et al. [7], because of two main weaknesses: the configurations for the calculation of the work of separation are usually limited to simple crystallographic planes, which is over-simplistic, and where the driving force for $\mathrm{H}$ localization is limited to the effect of the hydrostatic stress. This is not enough, by several orders of magnitude, to reach high local concentrations. This gave room for an additional mechanism where $\mathrm{H}$-stabilized vacancies can slowly diffuse, cluster and form crack nuclei that coalesce with the main crack (see [8] and references therein) [9,10]. This mechanism is supported by the observation by Fukai that multiple H occupancy of the vacancy can result in extremely high concentrations of vacancies [11]. It has been specifically observed in $\mathrm{Ni}$ [12], although at high temperature and high $\mathrm{H}$ pressure, but also in electrodeposited $\mathrm{Ni}$ [13]. At room temperature, it has been proposed that out of equilibrium vacancies, stabilized by $\mathrm{H}$, could be produced by localized plasticity [10].

A critical evaluation of this mechanism requires a systematic quantification of the H-vacancy cluster' properties $\left(\mathrm{VH}_{n}\right)$ : stability as a function of $\mathrm{H}$ concentration and $\mathrm{T}$, mobility, clustering and segregation to other crystalline defects. The subject of the present paper is the first step where a detailed calculation of the energetics is made (segregation energies of the isolated $\mathrm{H}$ and formation energy of the clusters containing several $\mathrm{H}$ ). In line with what was recently done for other metals [14-16], we apply Density Functional Theory (DFT) to $\mathrm{H}$ in $\mathrm{Ni}$ and carefully compare our results with what was previously predicted by the semi-quantitative Effective Medium Theory (EMT) [17-20] and implantationannealing experiments $[21,22]$. Three characteristic segregation energies were found. An incoherency has been recently pointed out between the interpretation based on EMT and Thermal Desorption Spectra (TDS) (see [11] p. 222). In EMT, the segregation of an isolated $\mathrm{H}$ atom is high and goes down when several $\mathrm{H}$ occupy the vacancy because of $\mathrm{H}-\mathrm{H}$ repulsive interactions. On the contrary, TDS shows that the low segregation energy (in absolute value) is observed in the dilute limit. We will show that our calculations reconcile experiments with theory and give a clear microscopic picture of trapping by single and multiple vacancies. They also constitute a reliable database upon which statistical models for $\mathrm{VH}_{n}$ stability and mobility can be built.

The paper is organized as follows. In the first section, the method is exposed. Then, preliminary calculations are performed with two goals: prepare configurations for $\mathrm{H}$ segregation (single/ divacancy), and study $\mathrm{H}$ in solution in the perfect bulk, since it is the reference state for segregation and several interstitial sites are in competition. The objective is also to reproduce some key quantities that appeared in the literature to firmly establish the coherency between our DFT calculations and those done in the past. As a side, we study the self interstitial because it is useful to interpret the implantation experiments. In the fourth section, comprehensive calculations of $m H$ atoms $(m<=13)$ in a vacancy are presented where we specifically investigate the $\mathrm{H}-\mathrm{H}$ interactions inside the vacancy and the possibility to form $\mathrm{H}_{2}$ molecules. The goal is to establish the maximum trapping capacity of the vacancy and to extract the typical segregation energy range that can be compared to experiments. In the last section, we extend the same approach to divacancies. Finally, the results are summarized and a simple picture of trapping, coherent with experiments, is established.

\section{Methods}

Calculations were performed using the Vienna $a b$ initio simulation package (VASP) [23-25]. The Kohn-Sham equations were solved by using the projector augmented wave (PAW) method [26] to describe the electron-ion interactions and using the Perdew-Wang (PW 91) approximation [27] for the exchange and correlation functionals. The magnetic moments taken into account in all calculations were necessary to avoid errors even at high temperature (see discussion page 5 in Ref. [28] on the differences between para- and ferromagnetic calculations).

The plane-wave cut-off energy was set to $400 \mathrm{eV}$ and $8 \times 8 \times 8$ Monkhorst-Pack mesh grids [29] were used to sample the Brillouin zone for the large supercells ( $3 \times 3 \times 3$, i.e., $108 \mathrm{Ni}$ atoms), which produced energy of segregation values converged to within $10 \mathrm{meV}$. These criteria have been validated in previous works $[30,28]$. Within these criteria, the ground states properties of fcc nickel (the lattice parameter, the cohesive energy and the magnetism are equal to $3.52 \AA$, $4.89 \mathrm{eV} /$ atom and $0.62 \mu_{B}$, respectively) agree with the previous DFT calculations [31] and the experimental values [32].

Lattice relaxations were introduced by means of a conjugategradient algorithm. The ions and the lattice parameters were allowed to relax. We ensure that the atomic forces were smaller than $0.01 \mathrm{eV} / \AA$ on the $\mathrm{H}$ and $\mathrm{Ni}$ atoms. It will be shown that, in most cases, the final configurations are symmetric even if the symmetry of the initial configurations is perturbed by random displacements of the $\mathrm{H}$ atoms prior to minimization.

\section{Preliminary calculations}

In this section, we briefly present the main properties of the defects that will be used later to trap $\mathrm{H}$ atom (vacancies and selfinterstitials). $\mathrm{H}$ in solution, in the perfect bulk, is also reviewed.

\subsection{Single and divacancies}

First, single and divacancies are studied. The formation enthalpy of an $n$-vacancy $\left(\mathrm{H}_{n v}^{f}\right.$, where $n=1$ or 2 ) is calculated. As the supercell is relaxed (the pressure on the supercell is equal to zero), the formation enthalpy is equal to the formation energy $\left(E_{n v}^{f}\right)$ in our approach. The $E_{n v}^{f}$ values were calculated as follows:

$E_{n v}^{f}=E_{o}\left[(N-n) \cdot N i, \Omega_{n}\right]-\frac{N-n}{N} E_{o}\left[N \cdot N i, \Omega_{o}\right]$

where $E_{o}\left[(N-n) \cdot N i, \Omega_{n}\right]$ and $E_{o}\left[N \cdot N i, \Omega_{o}\right]$ correspond to the internal energy of the relaxed supercell of a system with $n$-vacancies and that of the relaxed supercell of a system without any vacancies (i.e., $N$ nickel atoms). The formation volume $\left(\Omega_{n v}^{f}\right)$ of the defect is given by

$\Omega_{n v}^{f}=\frac{V[(N-n) \cdot N i]-(N-n) \cdot V_{a t}[N i]}{V_{a t}[N i]}$

Table 1

Formation energies ( $E_{n v}^{f}$, in units of $\mathrm{eV}$ ) and volumes of formation $\left(\Omega_{n v}^{f}\right.$, in atomic volume) of a single vacancy and first nearest neighbor (1NN) and second nearest neighbor (2NN) divacancies (per vacancy).

\begin{tabular}{llllll}
\hline & \multicolumn{3}{c}{$E_{n v}^{f} / n$} \\
& & & $\Omega_{n v}^{f} / n$ \\
& Our work & \\
\hline $\mathrm{V}_{1}$ & & 1.40 & $1.45 / 1.70[37,38]$ & 0.76 & $0.82-0.97[33]$ \\
$\mathrm{V}_{2}$ & $1 \mathrm{NN}$ & 1.37 & $1.49 / 1.73[33]$ & 0.64 & $0.79[33]$ \\
& $2 \mathrm{NN}$ & 1.42 & - & 0.65 & - \\
\hline
\end{tabular}




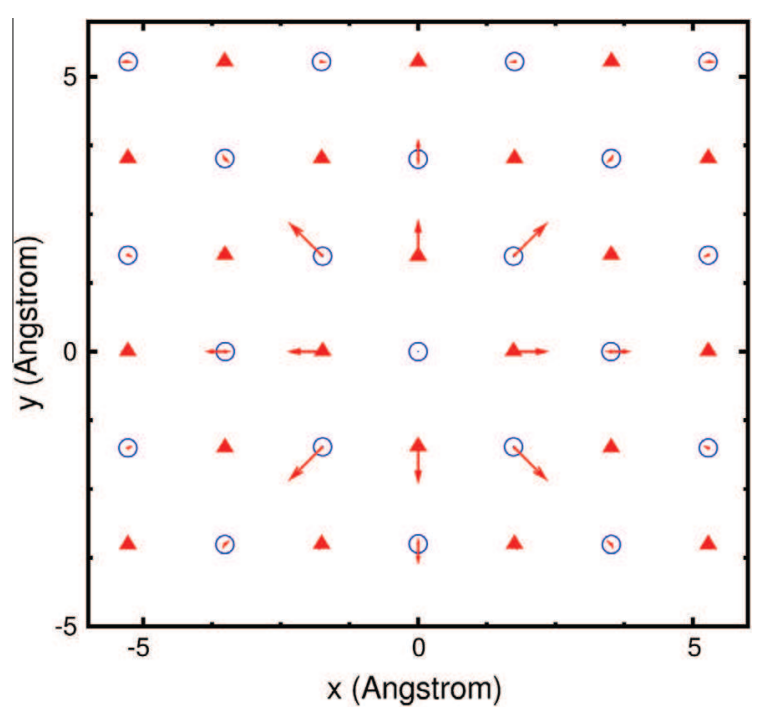

Fig. 1. Projected force field around a vacancy using Simonelli's procedure (see text). The vacancy is located at the center of the box $(0,0)$ : triangles and circles represent $\{200\}$ planes. Arrows represent the forces on atoms, their lengths are proportional to the norm of the strengths.

where $V_{a t}[\mathrm{Ni}]$ is the atomic volume of nickel in the fcc-structure $(V[N \cdot N i] / N)$. Table 1 compares the results with those presented in the theoretical literature [33]. DFT-GGA simulations without surface effects [34] underestimate the formation energies (approximately $1.7 \mathrm{eV}[35,36])$. In the case of the formation volume, our results are in agreement with those reported in the literature.

For the divacancy, two configurations are considered: the first and the second nearest neighbor configurations (labeled 1NN and $2 \mathrm{NN}$, respectively). The $1 \mathrm{NN}$ configuration, which is the most compact cluster, is the most stable divacancy.

We analyze the elastic field induced by the vacancy. To calculate the Kanzaki forces from the displacements at the point-defect core, we used the procedure proposed by Simonelli et al. [39]. Fig. 1 shows this force field. The forces around the vacancy decrease and become negligible beyond $5 \AA$. This result implies that at least the three first shells of octahedral sites feel the vacancy, as will be confirmed by the calculation of the $\mathrm{H}$ segregation energies in the next section. It is also noted that the force field is oriented away from the vacancy, which means that the interstitial sites are in traction (the forces are generated by the insertion of a particle in the vacancy). The stress induced by the single vacancy should attract the small interstitials. The effect of this radius of capture on the $\mathrm{H}$ diffusion will be considered in a forthcoming paper.

\subsection{Self-interstitials}

As mentioned by Norskov et al. [20], self-interstitials are supposed to play a non-negligible role in the trapping of hydrogen in metals. In fcc systems, self-interstitials adopt a so-called dumbbell structure. The main axis of the dumbbell is along the (100)

\section{Table 2}

Insertion $\left(E_{i}[\mathrm{H}]\right.$, in units of $\left.\mathrm{eV}\right)$, formation $\left(E_{\mathrm{s}}[\mathrm{H}]\right.$, in units of $\left.\mathrm{eV}\right)$, frequencies $(\omega$, in $\mathrm{cm}^{-1}$ ) and zero-point-energies (ZPE, in units of meV, see text) of the $\mathrm{H}$ atom in fcc nickel, $\Delta E=E_{s}[X$ site $]-E_{s}[0$ site $]$. Values from Ref. [41] have been computed at a fixed lattice parameter, $3.52 \AA$.

\begin{tabular}{llllll}
\hline Site & $E_{i}[\mathrm{H}]$ & $E_{S}[\mathrm{H}]$ & $\omega$ & ZPE & $\Delta E$ \\
\hline $\mathrm{O}$ & -2.912 & $0.088 / 0.08[41]$ & 791 & 150 & 0 \\
$\mathrm{~T}$ & -1.970 & $0.311 / 0.33[41]$ & 1285 & 238 & 0.222 \\
$\mathrm{~S}$ & -0.219 & 2.062 & $<0$ & - & 1.974 \\
\hline
\end{tabular}

direction, as explained by Schilling [40]. We find a high formation energy of the dumbbells, approximately $+3.96 \mathrm{eV}$, significantly higher than the formation energies of divacancies.

\subsection{Hydrogen in solution}

To compute the solubility of $\mathrm{H}$ atoms in nickel, a set of different equations for the insertion and the solubility energies (denoted $E_{i}$ and $E_{s}$, respectively) are used, according to the site studied:

$E_{i / s}[\mathrm{H}]=E_{o}[N \cdot N i+\mathrm{H}]-E_{o}[N . N i]-\mu_{a t / r e f}^{o}[\mathrm{H}]$

for the tetrahedral $(\mathrm{T})$ and the octahedral $(\mathrm{O})$ sites and

$E_{i / s}[\mathrm{H}]=E_{o}[(N-1) \cdot N i+\mathrm{H}]-\frac{N-1}{N} \cdot E_{o}[N \cdot N i]-\mu_{a t / r e f}^{o}[\mathrm{H}]$

for the substitutional site. $\mu_{a t}^{o}[\mathrm{H}]$ corresponds to the $\mathrm{H}$ atomic chemical potential, and $\mu_{\text {ref }}^{o}[\mathrm{H}]$ one-half of the $\mathrm{H}_{2}$ energy. For $\mathrm{H}_{2}$, we obtain a formation energy equal to $4.56 \mathrm{eV}$ (without the vibrational contribution), and the inter-atomic distance between hydrogens is equal to $0.75 \AA$. These results agree with the experimental values: $4.52 \mathrm{eV}$ and $0.74 \AA . E_{o}[N \cdot N i]$ corresponds to the energy of the perfect bulk, and $E_{o}[(N-1) \cdot N i+\mathrm{H}]$ and $E_{o}[N \cdot N i+\mathrm{H}]$ are the energies of the system with a interstitial $\mathrm{H}$ atom and with and without vacancy, respectively.

Table 2 shows the results for one $\mathrm{H}$ atom in nickel. As mentioned by Wimmer et al. [41], and in agreement with experimental observations [11], the $\mathrm{H}$ atoms are located preferentially in the octahedral sites. We obtain solution enthalpy values (including the zero-point-energy) of 100 and $411 \mathrm{meV}$ for the $\mathrm{O}$ and $\mathrm{T}$ sites, respectively.

The difference in energy between an $\mathrm{H}$ atom in substitution (i.e., positioned exactly at the center of a vacancy, the "S site") and in an octahedral site ( $\mathrm{O}$ site) confirms that the $\mathrm{H}$ atoms prefer to be located at the later position. Furthermore, the $\mathrm{O}$ site is approximately $0.22 \mathrm{eV}$ lower in energy than the tetrahedral site (T site). In comparison, in aluminum, an other fcc structure, we obtain [42] that +0.74 and $+0.91 \mathrm{eV}$ are required to insert an $\mathrm{H}$ atom in a tetrahedral and an octahedral site, respectively (without taking into account the zero-point-energy). These values agree well with the work by Wolverton et al. [43].

Then, the $\mathrm{H}$ frequencies and therefore the zero-point-energy (ZPE) (using $\sum_{i} \hbar \omega_{i} / 2$ at $0 \mathrm{~K}$ ) are computed. To a first-order approximation, only the $\mathrm{H}$ frequencies are calculated, neglecting the vibrations of the network. They are computed using a frozen mode approach, where the relative displacements are equal to 0.01 on $3 \times 3 \times 3$ supercells. We obtain one frequency, three times degenerated, equal to $791 \mathrm{~cm}^{-1}$ (i.e., approximately $100 \mathrm{meV}$ ) for the 0 site, and one frequency, three times degenerated, equal to $1285 \mathrm{~cm}^{-1}$ (approximately $159 \mathrm{meV}$ ) for the T site. The ZPE correction is therefore low: approximately 150 and $238 \mathrm{meV}$ for the 0 and the $\mathrm{T}$ sites, respectively. Finally, when we take into account the $\mathrm{ZPE}$ of the $\mathrm{H}_{2}$ molecule $\left(538 \mathrm{meV}=4351 \mathrm{~cm}^{-1}\right.$, i.e., a ZPE equal to $134 \mathrm{meV}$ ) the correction of the formation energy is low (approximately 12 and $100 \mathrm{meV}$ for $\mathrm{O}$ and $\mathrm{T}$ sites, respectively).

In the case where $\mathrm{H}$ is located at the center of a vacancy, we obtain three imaginary frequencies, which indicates that the configuration is not stable. The $\mathrm{H}$ atom prefers to move either towards the octahedral site or the tetrahedral site in the vacancy as detailed below.

\section{Interactions between hydrogen and self-interstitials}

As mentioned by Norskov et al. [20], self-interstitials are supposed to play a non-negligible role in the trapping of hydrogen 


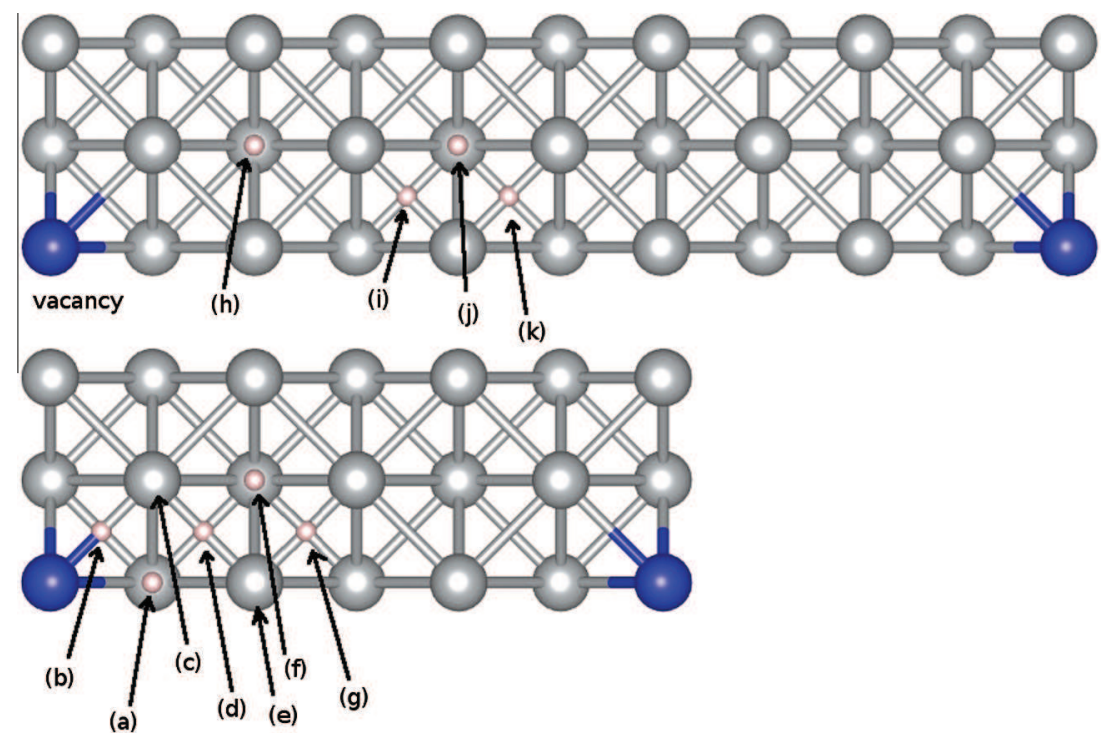

Fig. 2. Schematic illustration of the different positions of the $\mathrm{H}$ atoms inside and in the vicinity of the single vacancy. On top is the $5 \times 3 \times 3$ supercell and at the bottom is the $3 \times 3 \times 3$ supercell. The position of the vacancy is colored in blue. Labels correspond to the letters used in Table 3 . (For interpretation of the references to color in this figure legend, the reader is referred to the web version of this article.)

in nickel. The formation energy of the self-interstitial-hydrogen cluster is given by:

$E^{f}[\mathrm{H}, \mathrm{SIA}]=E_{o}[(N+1) \cdot N i+\mathrm{H}]-\frac{N+1}{N} \cdot E_{o}[N \cdot N i]-\frac{1}{2} E_{o}\left[\mathrm{H}_{2}\right]$

and the segregation energy of which corresponds to

$$
\begin{aligned}
E^{\text {seg }}[\mathrm{H}, \mathrm{SIA}]= & \left(E_{o}[(N+1) \cdot N i+\mathrm{H}]-E_{o}[(N+1) \cdot N i]\right) \\
& -\left(E_{o}\left[N \cdot N i+\mathrm{H}_{o c t a}\right]-E_{o}[N \cdot N i]\right)
\end{aligned}
$$

Two nearest neighboring configurations are possible for $\mathrm{H}$ in an octahedral site. In the first configuration, the $\mathrm{O}$ site is perpendicular to the axis of the dumbbell, and in the second the $\mathrm{H}$ atom occupies the $\mathrm{O}$ site aligned with the dumbbell. The calculations yield values of $4.03 \mathrm{eV}(0.07 \mathrm{eV})$ and $3.94 \mathrm{eV}(-0.02 \mathrm{eV})$ for the formation (segregation) energy for these two configurations, respectively. The second case seems slightly more favorable than the octahedral site in the bulk, but the binding is very weak and does not fit the picture provided by EMT [17].

Similar work has been performed for the tetrahedral configurations, which suggests a formation energy of $4.01 \mathrm{eV}(+0.06 \mathrm{eV})$, indicating that these configurations are not favorable.

As a conclusion, self-interstitials do not trap hydrogen, contrary to the results presented in previous studies [20].

Table 3

Formation ( $E^{f}$, in units of eV, without ZPE correction) and segregation energies ( $E^{\text {seg }}$, in units of eV) of $\mathrm{V}_{1} \mathrm{H}_{1}$ cluster according to the distance between the $\mathrm{H}$ atom and the vacancy. We present the vacancy-hydrogen distances and the site where the $\mathrm{H}$ atom is located. Notation: $\mathrm{V}=$ vacancy, $\mathrm{T}=$ tetrahedral site and $\mathrm{O}=$ octahedral site.

\begin{tabular}{llllr}
\hline$d(\mathrm{H}-\mathrm{V})$ & Site & & $E^{f}$ & \multicolumn{1}{c}{$E^{\text {seg }}$} \\
\hline 0 & $\mathrm{~V}$ & & 2.062 & +0.594 \\
1.137 & $\mathrm{~T}=\mathrm{T}_{1}$ & $(\mathrm{~b})$ & 1.223 & -0.245 \\
1.546 & $\mathrm{O}=\mathrm{O}_{1}$ & $(\mathrm{a})$ & 1.209 & -0.259 \\
2.890 & $\mathrm{~T}$ & $(\mathrm{~d})$ & 1.677 & 0.209 \\
3.008 & $\mathrm{O}=\mathrm{O}_{2}$ & $(\mathrm{c})$ & 1.421 & -0.048 \\
3.780 & $\mathrm{~T}$ & $(\mathrm{~g})$ & 1.674 & 0.205 \\
3.920 & $\mathrm{O}$ & $(\mathrm{h}, \mathrm{f})$ & 1.465 & -0.003 \\
5.272 & $\mathrm{O}$ & $(\mathrm{e})$ & 1.506 & 0.038 \\
6.290 & $\mathrm{~T}$ & $(\mathrm{i})$ & 1.698 & 0.228 \\
7.260 & $\mathrm{O}$ & $(\mathrm{j})$ & 1.454 & -0.016 \\
8.027 & $\mathrm{~T}$ & $(\mathrm{k})$ & 1.692 & 0.222 \\
\hline
\end{tabular}

\section{Interactions between hydrogen and a single vacancy}

In this section, we detail the interactions between hydrogen atoms and a single vacancy. The vacancy can be viewed as a dodecahedron: it is bounded by 6 squares and 8 triangles. The tetrahedral sites (which are in the first nearest position of the vacancy, labeled " $\mathrm{T}_{1}$ ") in the vacancy are located near the triangles, whereas the octahedral sites (in the first nearest position of the vacancy, labeled " $\mathrm{O}_{1}$ ") are in the cube bounded by the squares.

\section{1. $V_{1} H_{1}$ energetics}

The interactions between one hydrogen and one vacancy (the simplest cluster) are investigated. The different configurations are shown in Fig. 2 ( $\mathrm{T}_{1}, \mathrm{O}_{2}$ and around the vacancy). This examination allows for the analysis of $\mathrm{H}$-vacancy interaction based on the $\mathrm{H}$-vacancy distance. Two supercells are used: $3 \times 3 \times 3$ and $5 \times 3 \times 3$ supercells to reduce the effects of periodic boundaries.

We used the following set of equations for computing different quantities: the formation energy $\left(E^{f}\right)$, defined as in Eq. (4) by:

$E^{f}=E_{o}[(N-1) \cdot N i+m \cdot \mathrm{H}]-\frac{N-1}{N} \cdot E_{o}[N . N i]-\frac{m}{2} E_{o}\left[\mathrm{H}_{2}\right]$

the mean segregation energy $(\langle E\rangle)$ :

$$
\begin{aligned}
\langle E\rangle= & \left(E_{o}[(N-1) \cdot N i+m \cdot \mathrm{H}]-E_{o}[(N-1) \cdot N i]\right) / m \\
& -\left(E_{o}\left[N \cdot N i+\mathrm{H}_{o c t a}\right]-E_{o}[n \cdot N i]\right)
\end{aligned}
$$

where the reference state $\left(E_{o}\left[N \cdot N i+\mathrm{H}_{o c t a}\right]\right)$ is the energy of the supercell with one $\mathrm{H}$ atom in the $O$ site. $\langle E\rangle$ corresponds to the mean segregation energy according to the octahedral site in the bulk (without a vacancy). A negative value represents the energy gain (per $\mathrm{H}$ atom) when $m$ hydrogens are trapped in a single vacancy relative to being dispersed at $m$ independent octahedral interstitial sites. Finally, the segregation energy $\left(E^{\text {seg }}\right)$ is calculated by:

$$
\begin{aligned}
E^{\mathrm{seg}}= & E_{o}[(N-1) \cdot N i+m \cdot \mathrm{H}]+E_{o}[N \cdot N i] \\
& -E_{o}[(N-1) \cdot N i+(m-1) \cdot \mathrm{H}]-E_{o}\left[N \cdot N i+\mathrm{H}_{\text {octa }}\right]
\end{aligned}
$$

When $m=1$, we have $E^{\text {seg }}=\langle E\rangle$, and when $m>1$, the segregation energy depends of the ( $n-1)$ th configuration, obtained by removing one $\mathrm{H}$ from the $\mathrm{V}_{1} \mathrm{H}_{m}$ cluster (several configurations are possible). 
Table 3 shows these energies according to the hydrogen-vacancy distance, for one $\mathrm{H}$.

The $\mathrm{H}$ atom inside the vacancy is not located at its center, as suggested by the preliminary results presented above. The vacancy is restored (builds an $\mathrm{H}-\mathrm{V}$ "cluster"), which significantly decreases the energy of the system by approximately $0.8 \mathrm{eV}$. Trapping an $\mathrm{H}$ atom is therefore energetically more favorable than having two isolated defects. The preferred site is, as in the bulk, the octahedral site "in" the vacancy $\left(\mathrm{O}_{1}\right.$ position, with a formation energy equal to approximately to $1.2 \mathrm{eV}$ ). However, the difference in energy between the tetrahedral site $\left(T_{1}\right.$ configuration) and the $\mathrm{O}_{1}$ position is small, approximately $15 \mathrm{meV}$, much lower than the energy in the bulk $(\Delta(\mathrm{O}-\mathrm{T})=220 \mathrm{meV})$.

It is useful to compare this situation with an other similar (fcc) system: aluminum. Our results are completely different from the results obtained for aluminum. Using the same approach [42], we obtained energies of -0.32 and $+0.36 \mathrm{eV}$ for the $\mathrm{T}_{1}$ and the $\mathrm{O}_{1}$ site of fcc-Al. In comparison, an $\mathrm{H}$ atom located at the center of the vacancy costs $+0.46 \mathrm{eV}$. In fcc Al, the lowest-energy position for the $\mathrm{H}$ atom in the presence of a vacancy is at an off-center position close to a tetrahedral site adjacent to the vacancy site. (These results agree with those obtained by Wolverton [43], who found a value of $-0.33 \mathrm{eV}$.) In the case of nickel, there are more trap sites available than in $\mathrm{Al}$ : the tetrahedral could also be occupied by one $\mathrm{H}$ atom in addition to the octahedral site at low temperature and low $\mathrm{H}$ concentration. However, as we will see, when all $\mathrm{O}_{1}$ sites are occupied (high $\mathrm{H}$ concentration), occupying a $\mathrm{T}_{1}$ site is no longer favorable.

The optimized positions of the $\mathrm{H}$ atom in $\mathrm{T}_{1}$ and $\mathrm{O}_{1}$ are not exactly located in the ideal octahedral and the tetrahedral position;
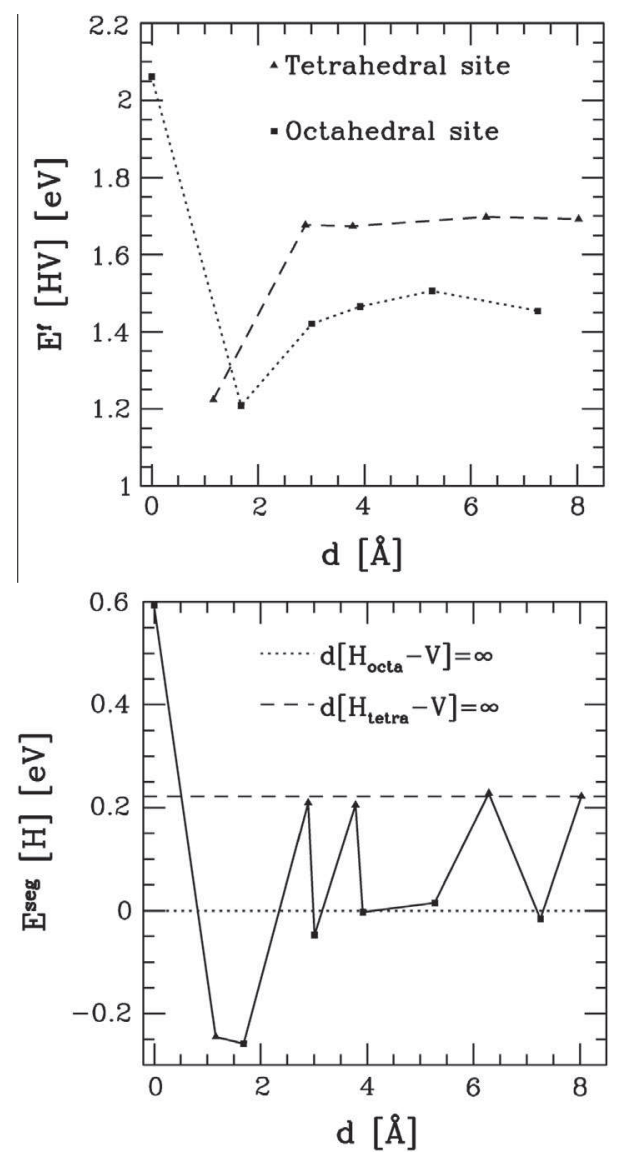

Fig. 3. Evolution of the formation (top) and segregation (bottom) energy according to the distance between the $\mathrm{H}$ atom and the vacancy. there is a slight offset from the $\mathrm{O}_{1}$ toward the vacant site. The ideal positions are at $1.52\left(\sqrt{3} / 4 a_{0}\right)$ and $1.76 \AA\left(a_{0} / 2\right)$ for the tetrahedral and octahedral sites of the vacancy, respectively. We obtain $\mathrm{H}$-vacancy distances of 1.14 and $1.55 \AA$, respectively. The "restored vacancy" attracts the $\mathrm{H}$ atom, i.e., the $\mathrm{H}$ atom moves 0.38 and $0.21 \AA ̊$.

One can also note that the $\mathrm{H}$-vacancy interactions rapidly decrease as the distance between the $\mathrm{H}$ and the vacancy increases (see Fig. 3). When the H-vacancy distance is greater than $5 \AA$, the interaction is close to zero. This configuration corresponds to the range of the interactions observed for the vacancy above (using the Kanzaki forces). We also note that the segregation energy of the next nearest configuration (the octahedral site, labeled $\mathrm{O}_{2}$ ) is slightly negative $(-0.05 \mathrm{eV})$. This segregation energy, in addition to $\mathrm{O}_{1}-\mathrm{O}_{2}$ attractive interactions, acts like a seed for hydride precipitation at high hydrogen concentration.

Finally, the vibrational correction of the $\mathrm{T}_{1}$ and $\mathrm{O}_{1}$ configurations are computed using the same approach used for the bulk. We obtain, respectively, three non-equivalent frequencies: 109, 106 and $132 \mathrm{meV}$ (i.e., 878, 857 and $1067 \mathrm{~cm}^{-1}$ ) and 105, 104 and $63 \mathrm{meV}$ (i.e., 848,845 and $509 \mathrm{~cm}^{-1}$ ). These values should be compared to the frequencies in the interstitial sites: 1285 and $790 \mathrm{~cm}^{-1}$ (see above). The ZPE for each configuration is thus low: 136 and $173 \mathrm{meV}$ for the $\mathrm{O}_{1}$ and $\mathrm{T}_{1}$, respectively. The ZPE does not significantly destabilize the $\mathrm{T}_{1}$ relative to the $\mathrm{O}_{1}$. The two highest frequencies correspond to the eigenvectors perpendicular to the H-vacancy bond. Throughout the vacancy, the frequencies are lower. The energy landscape around the $\mathrm{T}_{1}$ and $\mathrm{O}_{1}$ sites (not presented here) are observed to be flat.

In summary, the segregation energy (including the ZPE) is $-0.27 \mathrm{eV}$ on the $\mathrm{O}_{1}$ site, $-0.22 \mathrm{eV}$ on the $\mathrm{T}_{1}$ site and $-0.05 \mathrm{eV}$ on the $\mathrm{O}_{2}$ site. EMT [19] predicts a binding energy of $-0.4 \mathrm{eV}$, much

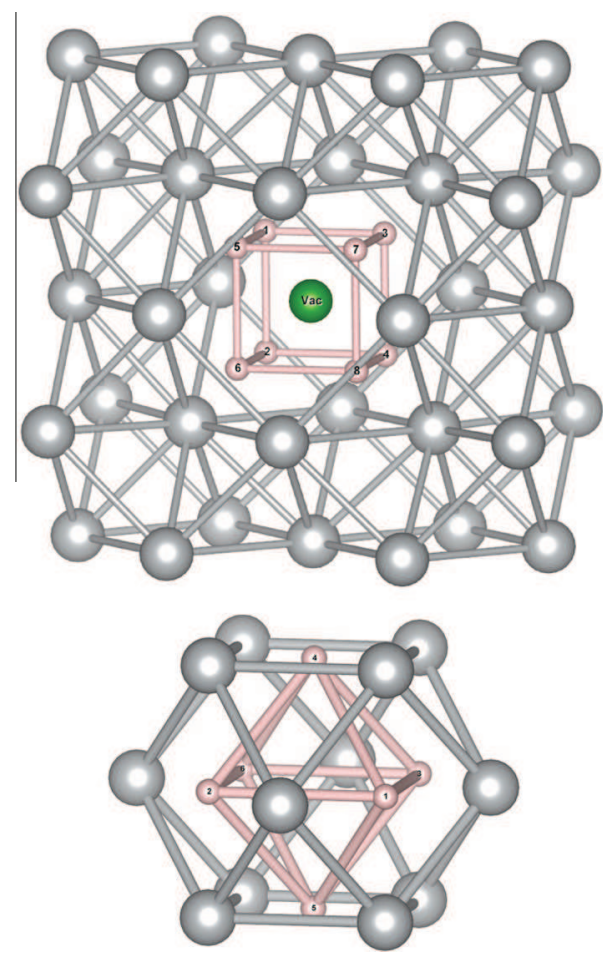

Fig. 4. Schematic illustration of the $\mathrm{VH}_{8}$ (top, all surrounding $\mathrm{Ni}$ atoms are represented) and $\mathrm{VH}_{6}$ (bottom) configurations, in $\mathrm{VH}_{8}\left(\mathrm{VH}_{6}\right)$, all $\mathrm{H}$ atoms are in the tetrahedral (octahedral) sites. Numbers are used in Table 4 to identify the configurations. The smallest ball are the $\mathrm{H}$ atoms, the vacancy is depicted in green. (For interpretation of the references to color in this figure legend, the reader is referred to the web version of this article.) 
Table 4

Degeneracy, formation, mean segregation and segregation and formation energies (in units of eV) and magnetic moment ( $\mu_{B}$, in Bohr's magneton, and $\mu_{B}^{*}$ in Bohr's magneton per $\mathrm{Ni}$ atoms) of the $\mathrm{V}_{1} \mathrm{H}_{m}$ clusters. For the segregation energy, the number of the $\mathrm{H}$ atom removed is given in brackets.

\begin{tabular}{|c|c|c|c|c|c|c|c|c|c|c|}
\hline$m$ & Sites & Deg & Config. & $E^{f}$ & $\langle E\rangle$ & & $E^{\text {seg }}$ & & $\mu_{B}$ & $\mu_{B}^{*}$ \\
\hline 0 & - & - & & 1.380 & - & - & & & 65.0 & 0.61 \\
\hline \multirow[t]{2}{*}{1} & $\mathrm{O}_{1}$ & 6 & 1 & 1.209 & -0.259 & $-0.259(1)$ & & & 64.3 & 0.60 \\
\hline & $\mathrm{T}_{1}$ & 8 & 1 & 1.223 & -0.245 & $-0.245(1)$ & & & 63.3 & 0.59 \\
\hline \multirow[t]{5}{*}{2} & $\mathrm{O}_{1}$ & 12 & 1,2 & 1.046 & -0.255 & $-0.251(2)$ & & & 63.9 & 0.60 \\
\hline & & 3 & 1,6 & 1.013 & -0.272 & $-0.285(6)$ & & & 63.8 & 0.60 \\
\hline & $\mathrm{T}_{1}$ & 12 & 1,2 & 1.285 & -0.136 & $-0.027(2)$ & & & 63.6 & 0.60 \\
\hline & & 12 & 1,7 & 1.129 & -0.214 & $-0.182(7)$ & & & 63.6 & 0.60 \\
\hline & & 4 & 1,8 & 1.085 & -0.236 & $-0.226(8)$ & & & 63.6 & 0.60 \\
\hline \multirow[t]{5}{*}{3} & $\mathrm{O}_{1}$ & 12 & $1,2,6$ & 0.865 & -0.260 & $-0.269(6)$ & $-0.236(2)$ & & 62.8 & 0.59 \\
\hline & & 8 & $1,2,4$ & 0.937 & -0.236 & $-0.198(4)$ & & & 63.0 & 0.59 \\
\hline & $\mathrm{T}_{1}$ & 24 & $1,2,3$ & 1.338 & -0.102 & $-0.035(3$ & $+0.121(2)$ & & 62.9 & 0.59 \\
\hline & & 24 & $1,2,8$ & 1.202 & -0.148 & $-0.171(8)$ & $-0.015(1)$ & $+0.029(8)$ & 62.9 & 0.59 \\
\hline & & 8 & $1,4,6$ & 1.069 & -0.192 & $-0.148(6)$ & & & 62.9 & 0.59 \\
\hline \multirow[t]{8}{*}{4} & $\mathrm{O}_{1}$ & 3 & $1,2,3,4$ & 0.703 & -0.257 & $-0.250(4)$ & $-0.322(3)$ & & 62.5 & 0.58 \\
\hline & & 12 & $1,2,3,6$ & 0.714 & -0.255 & $-0.239(3)$ & & & 62.5 & 0.58 \\
\hline & $\mathrm{T}_{1}$ & 2 & $1,4,6,7$ & 1.004 & -0.182 & $-0.153(7)$ & & & 62.3 & 0.58 \\
\hline & & 6 & $1,2,3,4$ & 1.489 & -0.061 & +0.063 & & & 62.3 & 0.58 \\
\hline & & 24 & $1,2,3,8$ & 1.251 & -0.121 & $-0.176(8)$ & $-0.040(3)$ & $+0.093(1)$ & 62.3 & 0.58 \\
\hline & & 24 & $1,2,4,8$ & 1.370 & -0.091 & $-0.057(8)$ & $+0.079(4)$ & & 62.3 & 0.58 \\
\hline & & 8 & $1,2,3,5$ & 1.335 & -0.100 & $-0.092(5)$ & $+0.177(1)$ & & 62.3 & 0.58 \\
\hline & & 6 & $1,2,7,8$ & 1.247 & -0.121 & $-0.043(7)$ & & & 62.3 & 0.58 \\
\hline \multirow[t]{4}{*}{5} & $\mathrm{O}_{1}$ & 6 & $1,2,3,4,5$ & 0.572 & -0.250 & $-0.219(5)$ & $-0.230(1)$ & & 61.8 & 0.58 \\
\hline & $\mathrm{T}_{1}$ & 24 & $1,2,3,4,5$ & 1.472 & -0.070 & $-0.109(5)$ & $+0.014(3)$ & $+0.049(4)$ & 61.6 & 0.57 \\
\hline & & 24 & $1,3,4,5,6$ & 1.393 & -0.086 & $-0.065(6)$ & $+0.054(5)$ & $+0.057(1)$ & 61.6 & 0.57 \\
\hline & & 8 & $1,2,3,5,8$ & 1.261 & -0.112 & $-0.162(8)$ & $-0.077(2)$ & $+0.169(1)$ & 61.6 & 0.57 \\
\hline \multirow[t]{4}{*}{6} & $\mathrm{O}_{1}$ & 1 & $1,2,3,4,5,6$ & 0.334 & -0.263 & $-0.327(6)$ & & & 61.5 & 0.57 \\
\hline & $\mathrm{T}_{1}$ & 12 & $1,2,3,4,5,6$ & 1.547 & -0.060 & $-0.013(6)$ & $+0.066(2)$ & & 60.9 & 0.57 \\
\hline & & 12 & $1,2,3,4,5,8$ & 1.462 & -0.074 & $-0.098(8)$ & $-0.018(3)$ & $+0.113(4)$ & 60.9 & 0.57 \\
\hline & & 8 & $1,3,4,5,6,8$ & 1.518 & -0.065 & $+0.037(8)$ & & & 60.9 & 0.57 \\
\hline 7 & $\mathrm{~T}_{1}$ & 8 & $1,2,3,4,5,6,7$ & 1.597 & -0.057 & $-0.038(7)$ & $-0.009(1)$ & $+0.047(3)$ & 60.2 & 0.56 \\
\hline 8 & $\mathrm{~T}_{1}$ & 1 & $1,2,3,4,5,6,7,8$ & 1.782 & -0.038 & $+0.096(8)$ & & & 59.4 & 0.55 \\
\hline
\end{tabular}

stronger than that yielded by DFT, in the dilute limit and an increase of up to $-0.2 \mathrm{eV}$ due to $\mathrm{H}-\mathrm{H}$ repulsion inside the vacancy. In the following section, we investigate $\mathrm{H}-\mathrm{H}$ interactions.

\section{2. $V_{1} H_{m}(m \leqslant 6$ octa, $m \leqslant 8$ tetra) energetics}

We now increase the number of $\mathrm{H}$ atoms in the vacancy. Because the segregation energies in the octahedral and the tetrahedral positions are similar, both sites are considered. For each $\mathrm{H}$ content $m$, we consider only the non-equivalent configurations. Each of these configurations is degenerated. It is possible to place the $m \mathrm{H}$ atoms in $p$ equivalent sites: $\frac{m !}{(p-m) ! p !}$ possibilities where $p=6$ for $\mathrm{O}_{1}$ and $=8$ for $\mathrm{T}_{1}$. We identify the non-equivalent configurations. Fig. 4 shows $\mathrm{H}$ positions in octahedral and tetrahedral positions in the vacancy. Numbers correspond to the $H$ positions used to describe the different configurations listed in Table 4.

Alternative cases are also considered (not reported here), where an $\mathrm{H}$ atom is placed at the vacancy center in addition to $m$ preexisting $\mathrm{H}$ at the $\mathrm{O}_{1}$ positions. In these cases, after relaxation, the $\mathrm{H}$ atom in the vacancy moves toward either an $\mathrm{O}_{1}$ or a $\mathrm{T}_{1}$ site, which confirms that the substitutional site is never stable, regardless of the $\mathrm{H}$ content.

We summarize our results in Table 4 . In addition to the energetic values, we list the magnetic moment $\left(\mu_{B}\right)$ according to the number of $\mathrm{H}$ atoms in the cluster. Different criteria are used in the literature to predict how many $\mathrm{H}$ atoms can be trapped in a vacancy $[44,45]$. The formation energy can be used in a thermodynamical formalism to compute the $\mathrm{VH}_{n}$ content [46]. The segregation energy itself is a bit more configuration dependent than the average segregation energy, but the essential message is that $\mathrm{O}_{1}-\mathrm{O}_{1}$ interactions are weak, contrary to the EMT predictions.

Our main result is that a single vacancy can trap up to six $\mathrm{H}$ atoms in the octahedral position. The average segregation energy is nearly constant, independent of the number of $\mathrm{H}$ atoms in the vacancy. From a configurational point of view, it is obtained that the final configurations are nearly symmetric. As the number of hydrogen increases, the $\mathrm{H}$ atoms are pushed toward the square $\mathrm{Ni}$ face, i.e., the ideal octahedral positions. This effect suggests that the $\mathrm{H}$ atoms repel one another. The mean distances between nearest $\mathrm{H}$ atoms are approximately $2.40-2.55 \AA$, much greater than in the diatomic $\mathrm{H}_{2}$ configuration.

For aluminum, Ismer et al. [45] and Lu and Kaxiras [44] proposed alternative configurations, in which the $\mathrm{H}$ atoms do not repel. The authors observed that one could place two $\mathrm{H}_{2}$ units in each $\langle 100\rangle$ direction surrounding the vacancy with a bond length of $1 \AA$ for all six units. For these configurations, the equilibrium inter-atomic distance between the $\mathrm{H}$ atoms at the vacancy is slightly longer than the $\mathrm{H}-\mathrm{H}$ bond length $(0.74 \AA)$ of the molecule in vacuum, which is due to the partial occupation of anti-bonding states between the $\mathrm{H}$ atoms. The inter-molecule distance in each direction is $3 \AA$, and the $N N$ distance between $\mathrm{H}$ and $\mathrm{Al}$ in each direction is $2 \AA$ (the lattice constant of $\mathrm{Al}$ is $3.99 \AA$ ). We test these configurations to determine if it is possible to restore diatomic molecules in a monovacancy in nickel. In the case of $\mathrm{Al}$, the $\mathrm{H}_{2}$ molecule is observed to be stable (we reproduced these results); but in nickel, it is not the case. This phenomenon can be correlated to the charge on the $\mathrm{H}$ atoms in solution in nickel. From the analysis of Bader's charges [47], the $\mathrm{H}$ atoms in the interstitial position and in interaction with a vacancy attract a small part of the electron of the surrounding $\mathrm{Ni}$, which implies a small negative charge on the $\mathrm{H}$ atoms: approximately $1.2,1.3,1.5$ and 1.3 electron around the $\mathrm{H}$ atoms in the $\mathrm{T}, \mathrm{T}_{1}, \mathrm{O}$ and $\mathrm{O}_{1}$ positions. In parallel, the magnetism decreases slightly as the number of $\mathrm{H}$ atoms increases $\left(\mu_{\mathrm{B}}\right.$ in Table 4). The $\mathrm{H}$ atoms repel one another and it is not possible to have a stable $\mathrm{H}_{2}$ molecule in a monovacancy, contrary to the case of aluminum. This result can also explain why the clusters formed 
Table 5

Segregation and formation energy (in units of eV) of the $\mathrm{V}_{1} \mathrm{H}_{m}$ according to the number of $\mathrm{H}$ atoms in the cluster.

\begin{tabular}{|c|c|c|c|c|c|c|c|c|c|}
\hline$m$ & Config. & $E^{f}$ & $\langle E\rangle$ & $E^{\text {seg }}$ & $m$ & Config. & $E^{f}$ & $\langle E\rangle$ & $E^{\text {seg }}$ \\
\hline \multirow[t]{2}{*}{7} & $\mathrm{OO}$ & 0.322 & -0.239 & -0.100 & 11 & $\mathrm{OO}$ & 0.235 & -0.192 & -0.115 \\
\hline & OT & 0.815 & -0.169 & +0.393 & & OT & 2.553 & 0.018 & +0.086 \\
\hline \multirow[t]{2}{*}{8} & $\mathrm{OO}$ & 0.308 & -0.222 & -0.102 & 12 & $\mathrm{OO}$ & 0.214 & -0.185 & -0.109 \\
\hline & OT & 1.273 & -0.102 & +0.370 & 13 & $\mathrm{OO}$ & 0.205 & -0.179 & -0.098 \\
\hline \multirow[t]{2}{*}{9} & $\mathrm{OO}$ & 0.281 & -0.210 & -0.115 & 14 & $\mathrm{OO}$ & 0.370 & -0.160 & -0.091 \\
\hline & OT & 1.738 & -0.048 & +0.376 & & & & & \\
\hline \multirow[t]{2}{*}{10} & $\mathrm{OO}$ & 0.264 & -0.200 & -0.105 & & & & & \\
\hline & OT & 2.346 & 0.008 & +0.382 & & & & & \\
\hline
\end{tabular}
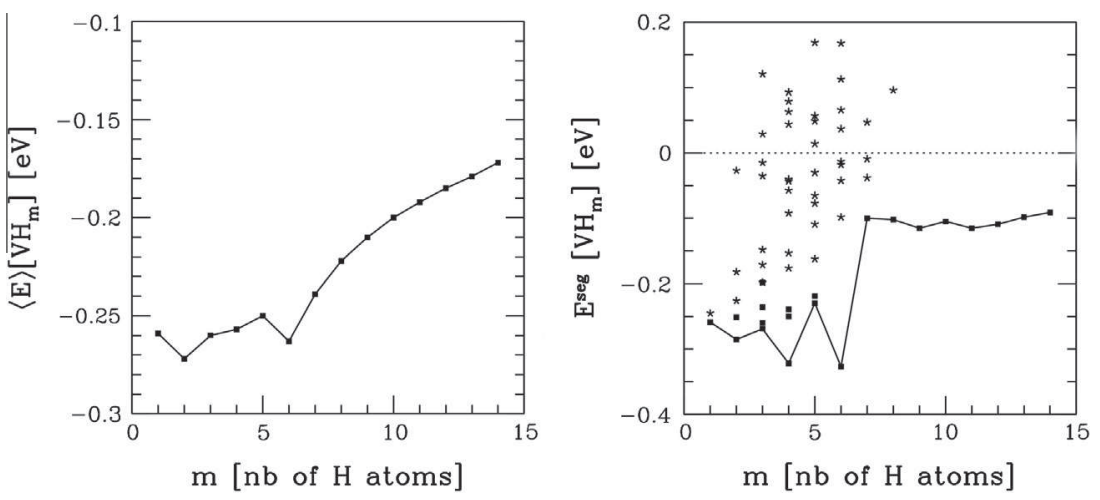

Fig. 5. Mean segregation $(\langle E\rangle)$ energies (left) and segregation $\left(E^{\text {seg }}\right)$ energies (right) according to the number of $\mathrm{H}$ atoms in a vacancy. Squares and stars represent octahedral and tetrahedral configurations, respectively.

by occupied $\mathrm{O}_{1}$ sites are more stable than those formed by occupied $T_{1}$ sites. The distance between sites is smaller in between $T_{1}$ sites than in between $\mathrm{O}_{1}$ sites: $1.6-1.7 \AA$ and $2.5-3.6 \AA$, respectively. For low concentrations, we can suppose that both sites can be filled alternatively, but when the electrostatic effects become considerable the $\mathrm{H}$ atoms are only located at $\mathrm{O}_{1}$ sites.

\section{3. $V_{1} H_{m}(m>6$ octa $)$ energetics}

We increase further the number of segregated $\mathrm{H}$ atoms. All of the octahedral sites in the vacancy are filled first, and $\mathrm{H}$ atoms are then progressively added, either at $\mathrm{T}_{1}$ positions or at $\mathrm{O}_{2}$ positions. To simplify, we only consider one configuration for each $m$, where $m$ is greater than 7 . We suppose that the interactions between the $\mathrm{H}$ atoms in $\mathrm{O}_{2}$ or $\mathrm{T}_{1}$ are negligible (the distance between two $\mathrm{H}$ atoms in $\mathrm{O}_{2}$ positions are large). The energies are presented in Table 5. Fig. 5 shows the final results regarding the segregation energies according to the number of $\mathrm{H}$ atoms.

We note that the segregation energy is always negative and increases slowly. The segregation energy of the tetrahedral sites is always found strongly positive, indicating that the vacancy is saturated when octahedral sites are completely filled. In contrast, at the $\mathrm{O}_{2}$ sites, the segregation energy of $\mathrm{H}$ atoms is always negative, approximately $-0.10 \mathrm{eV}$, showing that this site could be considered as a trap at low temperature and high concentration.

These results show that the vacancy can be considered as a trap composed of $6 \mathrm{O}_{1}$ sites, and eight additional sites $\left(\mathrm{O}_{2}\right)$ around the defect. These observations can be correlated to the results of the Section 3.1 on the Kanzaki forces, where the $\mathrm{O}_{2}$ sites appear to be in tension.

\section{Introduction to $\mathrm{V}_{2} \mathrm{H}_{m}$ clusters}

To conclude, we explore the capacity of larger vacancy clusters to trap hydrogen. To this end, we consider: $1 \mathrm{NN}$ and $2 \mathrm{NN}$ divacancies.

\section{1. $V_{2} H_{1}$}

We proceed in the same manner as in the previous section. Tetrahedral and octahedral positions in and around the divacancies are considered. The optimized positions are illustrated in Figs. 6 and 7 for $1 \mathrm{NN}$ and $2 \mathrm{NN}$ divacancies respectively.

Table 6 show the final values. To compute the segregation energy of $\mathrm{H}$ atoms on $1 \mathrm{NN}(2 \mathrm{NN})$, we used the energy of the empty $1 \mathrm{NN}(2 \mathrm{NN})$ energy as reference. Numbers correspond to the position of the $\mathrm{H}$ atoms around the divacancy as reported in Figs. 6 and 7 . In the case of $2 \mathrm{NN}$, the 7th configuration relaxes toward the first configuration, where the $\mathrm{H}$ atom is between the two vacancies.

The segregation energy is optimal inside the divacancy: configurations 4, 5 and 7 for the $1 \mathrm{NN}$, and 1, 2, 5, 8 and 9 for the $2 \mathrm{NN}$. Essentially, the trapping is similar to that in the case of a single vacancy; except at some remarkable positions where it is greatly enhanced, the segregation energy in $1 \mathrm{NN}$ can be as low as $-0.41 \mathrm{eV}$, and between vacancies (configuration 1) for $2 \mathrm{NN}$, $-0.487 \mathrm{eV}$.

These results are in excellent agreement with the thermal desorption data [21], which indicate three segregation energy ranges, one centered at $-0.24 \mathrm{eV}$, another close to $-0.43 \mathrm{eV}$ and a third close to $-0.55 \mathrm{eV}$ [22]. Our results suggest that the first value is characteristic of trapping to single vacancies, whereas the second one represents clusters involving more vacancies, as initially proposed by the authors of [21]. Unfortunately, the EAM potential [48], which works well for the segregation to the single vacancy, cannot capture these new features $\left(\Delta E_{\text {seg }}\right.$ is always close to $-0.22 \mathrm{eV}$ ). Therefore, it is difficult to use the EAM to track the interesting configurations with more than one vacancy.

\section{2. $\mathrm{V}_{2} \mathrm{H}_{2}$ clusters}

We also investigate the segregation of two $\mathrm{H}$ atoms in one $1 \mathrm{NN}$ divacancy. To simplify our investigation, we consider only the octa- 

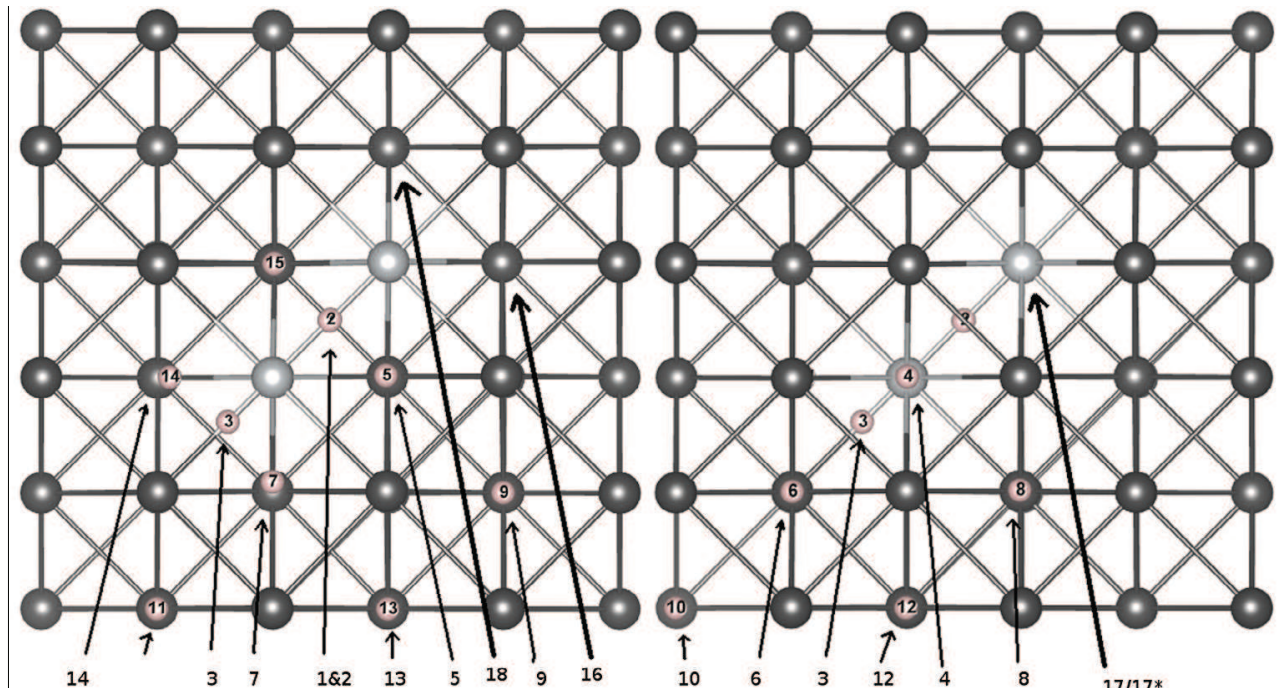

$\mathrm{H}$ in octahedral position
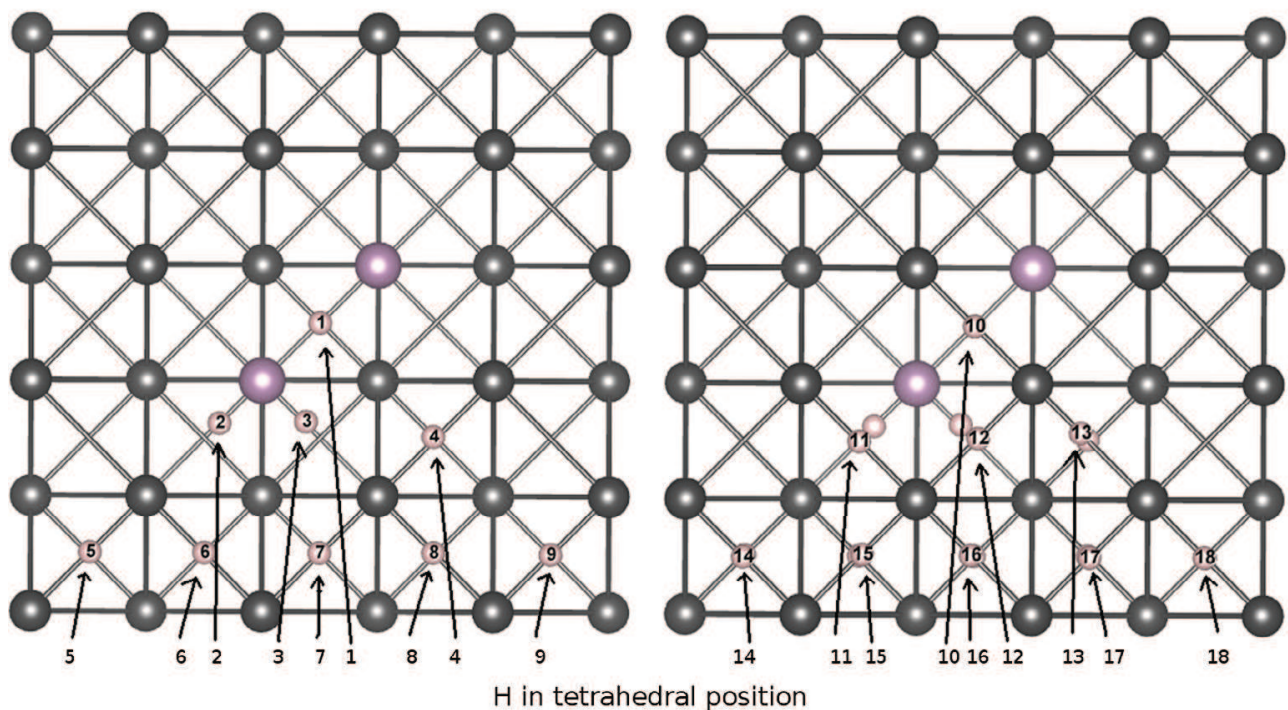

Fig. 6. Schematic illustration of the different hydrogen positions around a divacancy (1NN).
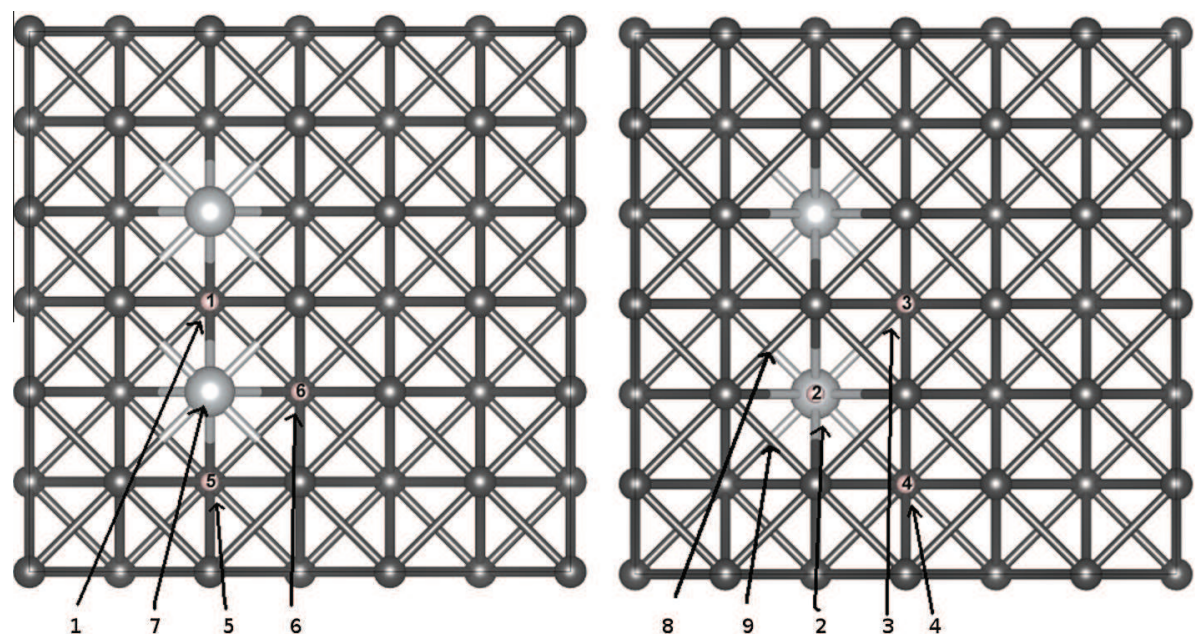

Fig. 7. Schematic illustration of the different hydrogen positions around a divacancy (2NN). 
Table 6

Formation and segregation (here $\langle E\rangle=E^{\text {seg }}$ ) energies of one $\mathrm{H}$ atom in 1NN. Energies are presented in units of eV. For hydrogen in octahedral sites $(1 \mathrm{NN})$, the case $1=2$, $14=7$, and $15=5$.

\begin{tabular}{|c|c|c|c|c|c|c|c|c|}
\hline \multirow[t]{2}{*}{ Site } & $\begin{array}{l}E^{f} \\
\text { in } 1 \mathrm{NN}\end{array}$ & $E^{\text {seg }}$ & $E^{f}$ & $E^{\text {seg }}$ & \multirow{2}{*}{\multicolumn{2}{|c|}{$\begin{array}{l}\text { Site } \\
\text { in } 2 \mathrm{NN}\end{array}$}} & \multirow[t]{2}{*}{$E^{f}$} & \multirow[t]{2}{*}{$E^{\text {seg }}$} \\
\hline & $\mathrm{O}$ sites & & $\mathrm{T}$ sites & & & & & \\
\hline 1 & 2.705 & -0.098 & 2.552 & -0.252 & $1=7$ & $\mathrm{O}$ & 2.420 & -0.487 \\
\hline 2 & & & 2.570 & -0.233 & $2=6$ & 0 & 2.660 & -0.246 \\
\hline 3 & 2.739 & -0.064 & 2.525 & -0.278 & 3 & $\mathrm{O}$ & 2.853 & -0.053 \\
\hline 4 & 2.497 & -0.306 & 3.001 & 0.198 & 4 & 0 & 2.877 & -0.029 \\
\hline 5 & 2.398 & -0.405 & 3.032 & 0.229 & 5 & $\mathrm{O}$ & 2.659 & -0.247 \\
\hline 6 & 2.776 & -0.028 & 3.033 & 0.230 & 8 & $\mathrm{~T}$ & 2.638 & -0.268 \\
\hline 7 & 2.558 & -0.245 & 3.037 & 0.233 & 9 & $\mathrm{~T}$ & 2.706 & -0.201 \\
\hline 8 & 2.770 & -0.033 & 3.033 & 0.230 & & & & \\
\hline 9 & 2.827 & 0.024 & 3.041 & 0.238 & & & & \\
\hline 10 & 2.794 & -0.009 & 3.009 & 0.206 & & & & \\
\hline 11 & 2.810 & 0.006 & 3.030 & 0.226 & & & & \\
\hline 12 & 2.807 & 0.004 & 2.988 & 0.185 & & & & \\
\hline 13 & 2.819 & 0.016 & 2.970 & 0.167 & & & & \\
\hline 14 & & & 3.056 & 0.331 & & & & \\
\hline 15 & & & 3.010 & 0.206 & & & & \\
\hline 16 & & & 3.029 & 0.226 & & & & \\
\hline 17 & & & 3.024 & 0.221 & & & & \\
\hline 18 & & & 3.019 & 0.216 & & & & \\
\hline
\end{tabular}

Table 7

Formation and segregation energies of two $\mathrm{H}$ atoms in $1 \mathrm{NN}$. Energies are presented in units of eV.

\begin{tabular}{clllllll}
\hline Site & Config. & Mult. & $\mathrm{d}(\mathrm{H}-\mathrm{H})$ & $E^{f}$ & $\langle E\rangle$ & $E^{\text {seg }}$ & \\
\hline 1 & $5-14$ & 4 & 3.52 & 2.218 & -0.332 & -0.269 & $-\mathbf{0 . 4 1 8}$ \\
2 & $7-14$ & 2 & 2.37 & 2.412 & -0.235 & -0.225 & - \\
3 & $14-16$ & 2 & 5.12 & 2.385 & -0.248 & -0.251 & - \\
4 & $14-17$ & 8 & 3.98 & 2.344 & -0.269 & -0.292 & -0.231 \\
5 & $14-15$ & 4 & 2.46 & 2.246 & -0.318 & -0.390 & -0.231 \\
6 & $14-18$ & 2 & 4.65 & 2.385 & -0.248 & -0.251 & - \\
7 & $14-4$ & 8 & 2.36 & 2.358 & -0.262 & -0.279 & -0.218 \\
8 & $4-17^{*}$ & 2 & 3.83 & 2.277 & -0.302 & -0.298 & - \\
9 & $4-17$ & 2 & 2.45 & 2.285 & -0.298 & -0.290 & - \\
10 & $17-17^{*}$ & 2 & 2.96 & 2.269 & -0.306 & -0.307 & - \\
11 & $5-4$ & 8 & 2.39 & 2.201 & -0.340 & -0.286 & -0.374 \\
12 & $5-15$ & 1 & 2.45 & 2.098 & $-\mathbf{0 . 3 9 2}$ & -0.379 & - \\
\hline
\end{tabular}

hedral sites described above, i.e., those inside the divacancy. In $1 N N$, there are 10 octahedral positions distributed in three nonequivalent octahedral sites: 2 are four times degenerated, and 1 is two times degenerated. Placing two $\mathrm{H}$ atoms in the octahedral sites yields 45 different configurations. We only considered nonequivalent positions (see multiplicity in Table 7); the numbers correspond to the octahedral positions presented in the previous section. Table 7 shows the results.

In all configurations, when the $\mathrm{H}-\mathrm{H}$ distance is large enough (except in configuration 2), the segregation energy is strongly negative. The segregation of two $\mathrm{H}$ atoms is a favorable process. As for the monovacancy, $\mathrm{H}_{2}$ molecules are not stable: when two $\mathrm{H}$ atoms are close, the interaction energy becomes repulsive (see the results for configuration " 2 "). The most favorable case corresponds to two $\mathrm{H}$ atoms in the most favorable configuration observed in the previous section (case 5 ).

In conclusion, divacancies should be stabilized by $\mathrm{H}$ atoms, at least at $\mathrm{H}$ concentration.

\section{Conclusion}

In this paper, we have presented a comprehensive study of $\mathrm{H}$ segregation on the dumbbell, the single and divacancies at $\mathrm{T}=0 \mathrm{~K}$ using the Density Functional Theory.
We showed that, contrary to the previous theoretical works, the dumbbells do not significantly trap $\mathrm{H}$. They should play a negligible role in $\mathrm{H}$ desorption experiments.

The study of the H-vacancies interactions showed that the first and second shells of interstitial sites attract $\mathrm{H}$, with a preference for $\mathrm{O}_{1}\left(\Delta E_{\text {seg }}=-0.259 \mathrm{eV}\right)$ versus $\mathrm{T}_{1}\left(\Delta E_{\text {seg }}=-0.245 \mathrm{eV}\right)$, which is essential: at finite temperature and away from the dilute limit, only $\mathrm{O}_{1}$ sites should be occupied because of the strong repulsion between $\mathrm{O}_{1}$ and $\mathrm{T}_{1}$ first neighbors. We also observe that up to six hydrogen atoms can be trapped in a vacancy. Contrary to Al, the $\mathrm{H}_{2}$ molecule is always unstable (even in the divacancy), whatever the $\mathrm{H}$ content. It can be explained by the net charge on the $\mathrm{H}$ atoms in the cluster. As a result, a further increase of the $\mathrm{H}$ content of the vacancy has to be made by occupying $\mathrm{O}_{2}$ sites where the segregation energy is much lower. The practical consequence is that an effective $\mathrm{H}$ diffusion model, in a field of vacancies, should consider the vacancy as 6 traps, but no more. Contrary to EMT, the $\mathrm{O}_{1}-\mathrm{O}_{1}$ interaction is weak and the average segregation energy is of the order of $-0.26 \mathrm{eV}$ (there is some scatter with values in between -0.33 and $-0.2 \mathrm{eV}$ ), in excellent agreement with the first peak of TDS $(-0.27 \mathrm{eV})[11]$.

From our results on divacancies (1NN and $2 \mathrm{NN}$ ), we showed that some octahedral positions of the divacancy have a much lower segregation energy, between -0.41 and $-0.39 \mathrm{eV}$, whereas the energies of other sites are similar to those of a single vacancy. These values could correspond to the second TDS peak $(-0.43 \mathrm{eV})[11]$.

An even larger value was obtained when $\mathrm{H}$ is in between two vacancies in $2 \mathrm{NN}$ which suggests that cavities provide even deeper traps than divacancies. These results suggest that the trapping energies -0.24 and $-0.43 \mathrm{eV}$ extracted from thermal desorption experiments may represent trapping to single and multiple vacancies, as was originally proposed by Besenbacher [21].

In forthcoming papers, we will present statistical models for the stability and the mobility of $\mathrm{VH}_{n}$ clusters, based on what is learned in this study.

\section{Acknowledgments}

This work was granted access to the HPC resources of CALMIP (CICT Toulouse, France) under the allocations 2013-p0912 and 2013-p0749. The authors acknowledge the support of the French Agence Nationale de la Recherche (ANR), under Grant EcHyDNA (Blanc 10-19424).

\section{References}

[1] A. Van der Ven, G. Ceder, Phys. Rev. B 67 (2003) 060101.

[2] H.K. Birnbaum, P. Sofronis, Mater. Sci. Eng. A 176 (1994) 191.

[3] T. Flanagan, N. Mason, H. Birnbaum, Scripta Metall. 15 (1981) 109.

[4] Q. Xu, A. Van der Ven, Phys. Rev. B 76 (2007) 064207.

[5] M. Martin, B. Somerday, R. Ritchie, P. Sofronis, I. Robertson, Acta Mater. 60 (2012) 2739.

[6] G. Scamans, R. Alani, P. Swann, Corr. Sci. 16 (1976) 443.

[7] H. Birnbaum, I. Robertson, P. Sofronis, D. Teter, in: Proceedings of CDI'96, Th. Magnin ed., The Institute of Materials, 1997, pp. 172-195.

[8] S.P. Lynch, in: Proceedings of CDI'96, Th. Magnin ed., The Institute of Materials, 1997, pp. 206-219.

[9] Y. Tateyama, T. Ohno, Phys. Rev. B 67 (2003) 174105.

[10] K. Takai, H. Shoda, H. Suzuki, M. Nagumo, J. Acta Mater. 56 (2008) 5158.

[11] Y. Fukai, The Metal-Hydrogen System: Basic Bulk Properties, 2nd ed., SpringerVerlag Berlin and Heidelberg GmbH \& Co. K, 2003.

[12] Y. Fukai, Y. Shizuku, Y. Kurokawa, J. Alloys Compd. 329 (2001) 195-201.

[13] Y. Fukai, M. Mizutani, S. Yokota, M. Kanazawa, Y. Miura, T. Watanabe, J. Alloys Compd. 356-357 (2003) 270-273.

[14] Y.-L. Liu, Y. Zhang, H.-B. Zhou, G.-H. Lu, F. Liu, G.-N. Luo, Phys. Rev. B 79 (2009) 172103.

[15] R. Nazarov, T. Hickel, J. Neugebauer, Phys. Rev. B 82 (2010) 224104.

[16] E. Hayward, C.-C. Fu, Phys. Rev. B 87 (2013) 174103.

[17] J. Nrskov, F. Besenbacher, J. Less-Common Metals 130 (1987) 475

[18] M. Puska, R. Nieminen, P. Jena, Phys. Rev. B 35 (1987) 6059. 
[19] P. Nordlander, J. Norskov, F. Besenbacher, S. Myers, Phys. Rev. B 40 (1989) 1990.

[20] J. Norskov, F. Besenbacher, J. Bottiger, B. Nielson, A. Pisarev, Phys. Rev. Lett. 49 (1982) 1420

[21] F. Besenbacher, J. Bttiger, S. Myers, J. Appl. Phys. 53 (1982) 3536.

[22] S. Myers, P. Nordlander, F. Besenbacher, J. Nrskov, Phys. Rev. B 33 (1986) 854

[23] G. Kresse, J. Hafner, Phys. Rev. B 47 (1993) 558.

[24] G. Kresse, J. Hafner, Phys. Rev. B 49 (1994) 14251.

[25] G. Kresse, J. Furthmüller, Phys. Rev. B 54 (1996) 11169.

[26] G. Kresse, D. Joubert, Phys. Rev. B 59 (1999) 1758.

[27] Y. Wang, J.P. Perdew, Phys. Rev. B 44 (1991) 13298.

[28] E. Megchiche, S. Pérusin, J.-C. Barthelat, C. Mijoule, Phys. Rev. B 74 (2006) 064111.

[29] H. Monkhorst, J. Pack, Phys. Rev. B 13 (1976) 5188.

[30] D. Kandaskalov, D. Monceau, C. Mijoule, D. Connétable, Surf. Sci. 617 (2013)

[31] D. Connétable, B. Ter-Ovanessian, E. Andrieu, J. Phys.: Condens. Matter 24 (2012) 095010.

[32] C. Kittel, Introduction to Solid State Physics, Wiley, New York, 1996.

[33] L.Y. Nemirovich-Danchenko, A.G. Lipnitskii, S.E. Kulakova, Phys. Solid State 49 (2007) 1079

[34] R. Nazarov, T. Hickel, J. Neugebauer, Phys. Rev. B 85 (2012) 144118.
[35] S. Nanao, K. Kuribayashi, S. Tanigawa, M. Doyama, J. Phys. F: Met. Phys. 7 (1977) 1403.

[36] J.L. Campbell, C.W. Schulte, J.A.S. Jackman, J. Phys. F: Met. Phys. 7 (1977) 1985.

[37] L. Delczeg, E. Delczeg-Czirjak, B. Johansson, L. Vitos, Phys. Rev. B 80 (2009) 205121.

[38] P. Nandi, M.C. Valsakumar, S. Chandra, H. Sahu, C. Sundar, J. Phys.: Condens. Matter 22 (2010) 345501.

[39] G. Simonelli, R. Pasianot, E. Savino, Phys. Rev. B 50 (1994) 727 (kanzaki forces).

[40] W. Schilling, J. Nucl. Mater. 69 (1977) 465 (self-interstitial in fcc and bcc metals).

[41] E. Wimmer, W. Wolf, J. Sticht, P. Saxe, C. Geller, R. Najafabadi, G. Young, Phys. Rev. B 77 (2008) 134305.

[42] We Employed the PBE Functional [49], Computed Using 333 Supercells, and $450 \mathrm{eV}$ for the Cut-off Energy.

[43] C. Wolverton, V. Ozolins, M. Asta, Phys. Rev. B 69 (2004) 144109.

[44] G. Lu, E. Kaxiras, Phys. Rev. Lett. 94 (2005) 155501.

[45] L. Ismer, M.S. Park, A. Janotti, C. VandeWalle, Phys. Rev. B 80 (2009) 184110.

[46] D. Tanguy, Y. Wang, D. Connétable, Acta Mater. (2014) (accepted for publication).

47] G. Henkelman, A. Arnaldsson, H. Jónsson, Comput. Mater. Sci. 36 (2006) 354.

[48] J. Angelo, N. Moody, M. Baskes, Modell. Simul. Mater. Sci. Eng. 3 (1995) 289.

[49] J. Perdew, K. Burke, M. Ernzerhof, Phys. Rev. Lett. 78 (1997) 1396. 